\title{
Information Technology and Corporate Strategy: A Research Perspective
}

\author{
J. Yannis Bakos \\ Michael E. Treacy \\ Center for Information Systems Research \\ Sloan School of Management \\ Massachusetts Institute of Technology \\ Cambridge, Massachusetts
}

This is a draft version of the article published in MIS Quarterly, June 1986, pp. 107-119

\begin{abstract}
The use of information technology (IT) as a competitive weapon has become a popular cliché; but there is still a marked lack of understanding of the issues that determine the influence of information technology on a particular organization and the processes that will allow a smooth coordination of technology and corporate strategy. This article surveys the major efforts to arrive at a relevant framework and attempts to integrate them in a more comprehensive viewpoint. The focus then turns to the major research issues in understanding the impact of information technology on competitive strategy.
\end{abstract}

Copyright (C) 1986 Yannis Bakos and Michael Treacy

Keywords: information technology and corporate strategy, information systems applications, management of information systems, competitive information systems.

ACM Categories: H.4, H.4.0, H.4.2, K.6, K.6.0 


\section{Introduction}

There is little disagreement about the strategic importance of information technology. Indeed, the potential use of information technology as a competitive weapon has already become a popular cliché. Literature in this area abounds with a number of frameworks for identifying and categorizing opportunities. There has been a notable absence, however, of testable models based on relevant theory. As this area of research matures, there is an increasing need to move beyond frameworks and toward explanatory models of the underlying phenomena. This type of research will allow us to build a cumulative tradition and to make normative statements to guide managerial actions.

This article moves toward the development of such normative models by distinguishing three levels at which information technology impacts corporate strategy: the internal, competitive, and business portfolio levels. It discusses a number of relevant general theories and provide a link with the disciplines of organizational design and industrial economics. Furthermore, it offers an operationalized definition of information technology which can be used to develop specific theories and models at each of the three strategic levels.

\section{Information Technology and Corporate Strategy}

Senior executives, strategic planners, and information systems managers are increasingly turning their attention to opportunities for achieving competitive advantage through information technology. There are several explanations for this recent trend, not the least of which is the publicity received by companies that have gained significant advantage through information technology $[5,11,12]$. The unstable economic conditions of the last few years have helped to create a challenging business environment and an "economic imperative" for information technology [3]. The technology is also offering a greater array of capabilities at lower costs than ever before. Finally, firms' abilities to utilize the technology are also improving. The transaction processing and decision support systems already in place in most firms provide a base on which systems for competitive advantage can be built. Without this base, many of these systems would not be possible.

Several authors have identified the underutilization of information technology as a serious problem facing both information systems and business managers $[3,14,31]$. Technology-based competitive opportunities are overlooked because of: (1) senior management's ignorance of information technology and its potential uses, (2) poor communications between the information systems group and the rest of the business, (3) resistance to change, among both information systems and business personnel, (4) a lack of focus on opportunities for competitive advantage, and (5) a lack of instruments to measure benefits.

Suggestions to draw attention to the capabilities of information technology range from the development of better measures of the efficiency and effectiveness of organizational functions, to major changes in the current structure of organizations. For example, Gerstein and Reisman [14] identify a need for the development of measures of the impacts of information systems on specific functions. Keen [22] suggests that important 
changes in the fundamental nature of work and the structure of organizations are needed, so that better use of information technology can be made. He predicts that information technology will become the backbone of corporations, and that organizations will develop around their telecommunication systems. McFarlan and McKenney [27, 28] point out the importance of proper management for the successful deployment of information technology. The mission and management of the information systems group should be consistent with the firm's dependency on technology and the opportunity for competitive advantage that the technology represents. Similar suggestions have been made about the need to reposition and expand the information systems function $[3,14,23,41]$ and the need for senior management education in information technology [3, 14, 20, 22].

These recommendations for increasing the utilization of IT focus on correcting organizational deficiencies that have restrained its effective use. Other researchers have focused on the potential for information technology to improve strategic performance. They have worked to develop tools and methodologies to help the manager find valuable opportunities for IT within his or her organization. This is the perspective in the present paper.

Opportunities arising from information technology can be viewed from three perspectives: (1) that of an organizational designer trying to improve the efficiency and effectiveness of the current organization, (2) that of an industry insider trying to outmaneuver other participants in a competitive game, and (3) that of an outsider investigating whether to enter an industry. These perspectives represent three major strategic views: internal, competitive, and business portfolio. Internal strategy is concerned with the development of efficient and effective organizational structures and processes for achieving goals and objectives. Competitive strategy focuses on competitive moves within the industries in which the organization does business. Business portfolio strategy concerns the choice of which industries to compete in and how to position the organization in those industries.

These components of corporate strategy are closely related, and information technology can affect all three simultaneously. For example, a firm in the distribution business may build an online order entry system, and place terminals in customer's purchasing departments. This system can improve the efficiency of the firm's operations, which is an element of internal strategy. The terminal can supply the customer with useful information, and by speeding orders can help the customer to reduce inventories. This increases switching costs for the customer and makes it more difficult for other distribution firms to compete, thus contributing to the competitive strategy of the firm. The order entry system may also be an important asset in other industries, such as mailorder retailing. Thus, the firm might enter this industry on the strength of its technology, which would impact the business portfolio strategy.

\section{Information Technology and Internal Strategy}

Improving the efficiency and effectiveness of organizations is the traditional domain of the information systems function. Rockart and Scott Morton [35] have suggested that traditional information systems also can have important implications for the competitive position of the firm. They employ a modification of Leavitt's organizational model [24] to show that these systems can affect competitive performance through their impact on management processes, personnel, and organizational structure. 


\section{Internal Strategy and MIS}

There are more than two hundred published papers or techniques for identifying opportunities to support management processes with information technology. Several detailed reviews have been published $[2,8,10,29,34,38]$. These techniques differ in focus, emphasis, and applicability to particular areas of concern.

Traditional approaches to identify areas for the application of information technology have focused on its capability to improve specific functional areas of the firm. The first generation of methodologies utilized a strictly operational view of the firm, with an objective to improve the efficiency of requisite business processes. Representative of this approach are business systems planning (BSP) [18], and office automation methodology (OAM) $[17,37]$. These techniques represent ways of formally modeling the operations of the enterprise so that potential improvements in efficiency and effectiveness can be analyzed. They are not easily applied to poorly structured functions, such as senior management roles, which are not amenable to formal modeling. The critical success factors (CSF) methodology [4, 34] has been used successfully in these unstructured environments to discover their latent structure. This structure, composed of business goals and related causal success factors, substitutes for a formal model of the functional area, and can be analyzed for opportunities to improve operating performance through the application of information technology.

All of these approaches fall short of treating strategic considerations as the driving force for the identification of IT opportunities. Furthermore, each is based on an implicit, idiosyncratic theory of organizations that is not grounded in the main body of organizational design literature. Although some of these theories are inventive, they neither contribute to, nor are leveraged by the accumulated knowledge of organizational theory. They are only private theories of organizational design, embedded within traditional MIS techniques.

\section{Information technology and organizational design}

We believe that a general theory for studying the implications of IT for the internal strategy of the firm can be found within the organizational design literature. Such a general theory would provide a framework of models for generating specific, testable hypotheses. It would identify the key, relevant variables and provide a methodological tradition within which to work. We propose that the construct of bounded rationality provides a major link between information technology and organizational design. Bounded rationality at the individual level refers to neurophysiological limitations to the information processing capacities (memory, computation and communication) of an individual. It is demonstrated in limits on the complexity and size of problems that can be solved by humans. Information technology can directly affect the computational and communication abilities of a decision-maker, thus shifting the limits of rationality.

Bounded rationality has been a key concept in the development of organizational theory. The information processing view of organizations, advanced by March and Simon [26], Cyert and March [9], Galbraith [13] and others, has asserted that human limitations on information processing interact with environmental factors such as environmental complexity and uncertainty to give rise to organizational problems. From this school's perspective, organizations are designed to marshal sufficient information processing and communications capabilities to be able to manage the complexity and uncertainty inherent in the environment. 
In the more recent transaction cost view of organizations, Williamson [39] asserts that constraints on human information processing are a major reason for the very existence of organizations. An alternative to organizations is to have economic agents acting independently and contracting to sell their services to one another in a marketplace. With unbounded rationality, every participant could counteract the effect of other participants' deceptive, self-interested behavior. In a world of bounded rationality, however, such opportunistic behavior in small marketplaces creates inefficiencies in the form of excessive contracting and transaction costs. To avoid these costs, individuals form organizations where interests are pooled. The transaction cost view can provide a new perspective on the role of information systems in organizations [7].

In both the information processing and the transaction cost schools of organizational theory, bounded rationality plays a pivotal role. Therefore, to explain the role of IT in improving internal strategy, we must characterize systems in terms that are relevant to bounded rationality. For example, "instruction processing speed" and "range and depth of system functions" are different aspects of processing capacity, but they are not equally relevant to a bounded rationality view of organizations. The former measures only technical capacity, whereas the latter can be directly linked to reducing human limitations in organizations.

The range of organizationally relevant measures of systems can be described using two dimensions of information technology, namely the functional components of a system (storage, processing and communications) and the performance characteristics of these components (capacity, quality, and unit cost). Each of the functional components maps directly onto a limitation in human cognitive capacities and, when combined with the performance characteristics, they form a 3 by 3 characterization matrix [1]. In Figure 1 we have illustrated this matrix and provided some examples of measures that are relevant to an organizational view of information technology.

\begin{tabular}{|c|c|c|c|}
\hline & Storage & Processing & $\begin{array}{c}\text { Communication } \\
\mathrm{s}\end{array}$ \\
\hline Capacity & $\begin{array}{l}\text { breadth and } \\
\text { depth of } \\
\text { databases }\end{array}$ & $\begin{array}{l}\quad \text { range and } \\
\text { depth of } \\
\text { system } \\
\text { functions }\end{array}$ & $\begin{array}{c}\text { size of } \\
\text { network } \\
\text { population }\end{array}$ \\
\hline Quality & $<\begin{array}{c}\text { appropriate } \\
\text { ness of data }\end{array}$ & $<\quad$ ease of use & $<\begin{array}{r}\text { appropriate } \\
\text { ness of media }\end{array}$ \\
\hline Unit Cost & $\begin{array}{c}<\text { cost of data } \\
\text { management }\end{array}$ & $\begin{array}{l}<\begin{array}{c}\text { cost per } \\
\text { transaction }\end{array} \\
<\begin{array}{c}\text { cost per } \\
\text { user }\end{array}\end{array}$ & $\begin{array}{l}\text { cost per } \\
\text { message }\end{array}$ \\
\hline
\end{tabular}

Figure 1. A Characterization of Information Technology

The major premise of this discussion is that information technology affects the efficiency and effectiveness of the organization primarily by reducing the bounded rationality of individual and group decision making. Research is needed to confirm or disprove this causal relationship. In particular, we need to study the impact of different forms of 
information technology, as categorized in Figure 1, on the factors that constrain the performance of individual and group decision makers. A good deal of effort has already been expended studying the link between information systems and managerial performance $[15,16,25]$. More headway could be made in this important area if a common characterization of information technology was used across studies and if the intervening variables that act as boundaries to rationality, and hence managerial performance, were identified and included in the study.

Our understanding of the link between limits on human information processing and organizational design was greatly expanded by the work of Jay Galbraith [13]. He argued that new organizational structures are created to close the information gap between requisite information processing needs of a firm and available information processing capacity. Further research is needed to understand what new organizational forms will be facilitated by future generations of information technology.

\section{Information Technology and Competitive Strategy}

A number of authors have identified opportunities for the application of information technology to create competitive advantage. Two general approaches can be distinguished: a value-added chain analysis of the firm's operations and Porter's framework for competitive analysis [32].

Rockart and Scott Morton [35] have introduced the use of the value-added chain to describe the potential opportunities arising from information technology. They identify three types of opportunities that can create competitive advantage: (1) improve each value adding function, (2) link with customers and suppliers to increase their switching costs, and (3) create new businesses through service or product. Ives and Learmonth [19] further this effort by using a generic, thirteen function resource lifecycle model to identify competitive opportunities. It should be noted that these value-added chain analyses, geared toward operational efficiency and functional effectiveness, are closely related to internal strategy.

Porter [32] advanced the idea that competition in any industry is rooted in its underlying economic structure, and thus it is more than a superficial game of moves and countermoves among participating firms. This approach is reflected in the framework he proposed to explain the dynamics of competition in an industry. As Figure 2 illustrates, five major forces underly competition: rivalry among existing competitors, threat of new entrants, threat of substitute products or services, bargaining power of suppliers, and bargaining power of customers. 


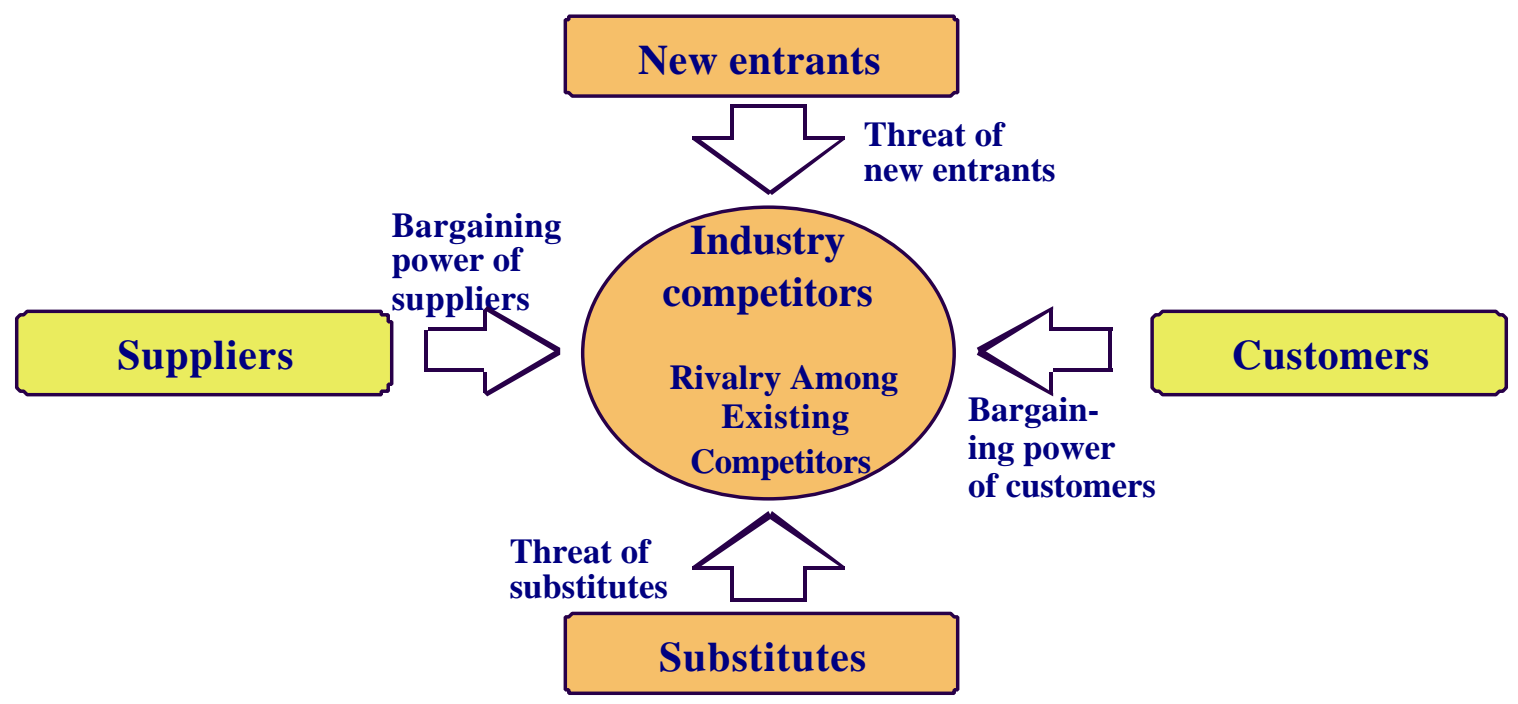

Source:Michael E. Porter,Competitive Strategy

Copyright 1980 by The Free Press. Used by permission.

Figure 2. Porter's Framework for Competitive Forces

An important implication of this framework is the idea of extended rivalry. To understand competition in an industry, one must look beyond current competitors to include customers, suppliers, firms producing substitute products, and potential entrants. Firms generally try to manipulate the competitive forces in their industry in order to achieve comparative advantage over competitors. There are certain generic strategies that can be employed to that end. Porter has identified cost leadership and product differentiation as two such strategies. He identifies a third strategy, the pursuit of niche markets, which is similar to product differentiation strategies. Other such strategies may include the exploitation of potential synergies with a firm's customers or suppliers, or the notion of gaining bargaining advantage over one's customers and suppliers.

Parsons [30] uses Porter's competitive forces framework to identify six generic categories of opportunities for competitive advantage: (1) increase customer's switching costs through value-adding IT-based information or service, (2) decrease one's own switching costs against suppliers, (3) use IT to support product innovation for purposes of maintaining one's position or deterring potential substitutes, (4) cooperate with selected rivals through shared IT resources, (5) substitute information technology for labor, and (6) use information to better segment and satisfy one's customer base.

\section{Four areas of opportunity}

Parsons, Rockart and Scott Morton, Ives and Learmonth, and others each have different categorizations of competitive opportunities created by information technology. From these we have distilled four areas of opportunity for IT to support competitive strategy, which are: (1) improvement of operational efficiency and functional effectiveness,

(2) exploitation of interorganizational synergies, (3) product innovation with IT, and

(4) acquisition of bargaining advantage over one's customers and suppliers. 


\section{Operational efficiency and functional effectiveness}

Systems to improve operations are the traditional focus of information technology applications and central to the support of the internal strategy of the firm. These systems can also support the competitive position of the firm to the extent that they may become industry innovations which can be turned into competitive advantage. Usually this requires that the system be applied to critical functional areas of the firm and that it be a new type of application in its industry. Simply following the industry leaders leads to competitive parity at best.

As discussed in the previous section, opportunities for operational efficiency are found in supporting organizational structure and management processes. Techniques for identifying them are well established, but unrelated to the body of organizational theory. Although opportunities to improve operational efficiency and effectiveness are the best understood, they are also, in many firms, the least important for competitive strategy.

\section{Cooperative information systems}

We can extend the concepts of improved operational efficiency and functional effectiveness beyond the boundaries of a single firm, typically in the context of interorganizational information systems. Competitive strategies for exploiting synergies with customers or suppliers generally concentrate upon opportunities for better coordination. Through better coordination, operations can be made more efficient to the benefit of all participants. Coordination can be achieved with information systems that couple functional areas in two distinct firms. For example, one might couple the production planning system of a firm with the order entry system of suppliers to lower the amount of inventory in process and the turnaround time for new orders.

Interorganizational systems are a new phenomenon. They allow firms to integrate their information-related activities (vertical information integration) without disturbing the legal boundaries of the entities involved. Cash and Konsynski point out that such systems may eventually redefine the boundaries of entire industries [6]. Methodologies to identify opportunities for cooperative systems may be quite similar to those used to improve operational efficiency and functional effectiveness; the main difference is that the unit of analysis becomes two organizations instead of just one.

\section{Product innovation with information technology}

Information technology is providing firms with unique opportunities for product innovation. In many industries, from automotive to consumer electronics, information technology is being built into existing products to enhance their value. In other industries, such as banking, insurance, and consulting, the technology is providing a development and delivery vehicle for new service-based products. The technology can provide an important means for differentiating existing products and developing new and unique ones.

\section{Creation of bargaining advantage against customers and suppliers}

An important tactic for improving one's bargaining position relative to customers is to provide unique and valuable information and services that require idiosyncratic changes to the customer's organization, and thus makes switching to a competitor more costly. Information technology can facilitate unique information or service offerings, previously unavailable and potentially of very great value to customers. The higher the perceived 
value of these offerings, and the more complex and idiosyncratic the interface is for the customer, the higher the switching costs imposed on the latter.

Every supplier is a customer of another supplier in an unbroken value-added chain. Thus, the opportunity to gain bargaining advantage can be pursued by one's suppliers to the firm's disadvantage, unless tactics are devised to avoid the problem. Two specific tactics present themselves: avoid becoming dependent on supplier-controlled information and services, and create an efficient "electronic marketplace" between one's own organization and its suppliers.

Some fundamental research is needed before a methodology can be developed for the identification of specific IT opportunities within this area. We must better understand how and when information and service creates sufficient dependency to impose a switching cost. We also need to understand how potential opportunities for developing new information and innovative service can be identified. Game theory and agency theory are two reference disciplines that have been used to study similar situations in industrial economics, and their potential applications for competitive information systems should be investigated.

\section{A theoretical framework}

The categorization of opportunities identified above can provide a useful framework for an industry insider trying to out-maneuver the other participants in a competitive game, but its value is limited by the lack of an underlying general theory. We can observe, however, that the first two types of opportunities are related to comparative efficiency, which refers to the ability of a firm to produce a product at a lower price relative to other products perceived as equivalent, while the last one is primarily related to the acquisition of bargaining power, which refers to the ability of a firm to resolve zero-sum bargaining situations, usually against its customers or suppliers, to its advantage. Product innovation with information technology could affect either comparative efficiency (e.g., by reducing production costs) or bargaining power (e.g., by increasing product uniqueness and customer switching costs).

Bargaining power and comparative efficiency are important concepts in the industrial economics discipline, and can form the basis for a simplified theory of competitive advantage. Competitive advantage, closely related to the concept of market power, refers to the ability of a firm to create and exploit monopoly or monopsony power. Bargaining power and comparative efficiency can be seen as the two major sources of competitive advantage, as shown in Figure 3. These two sources are more or less independent.

\section{Bargaining power}

In most game-theoretic situations, each side can improve its position, that is, develop competitive advantage, by increasing the number of available alternatives. This number is limited by the cost of the search process, which is determined by two primary factors: the information processing capacity of the player in question, as it relates to their efficiency in exploring the space of feasible alternatives, and the characteristics of the underlying search set, in terms of the number of feasible alternatives available for a given search effort. It is important to distinguish between alternatives available before and after a relationship is established, as that event may impose restrictions on one or both parties. Ex-ante alternatives are primarily determined by unique product features, while ex-post alternatives are also affected by switching costs arising from the imperfect transferability of assets specific to a transaction. 


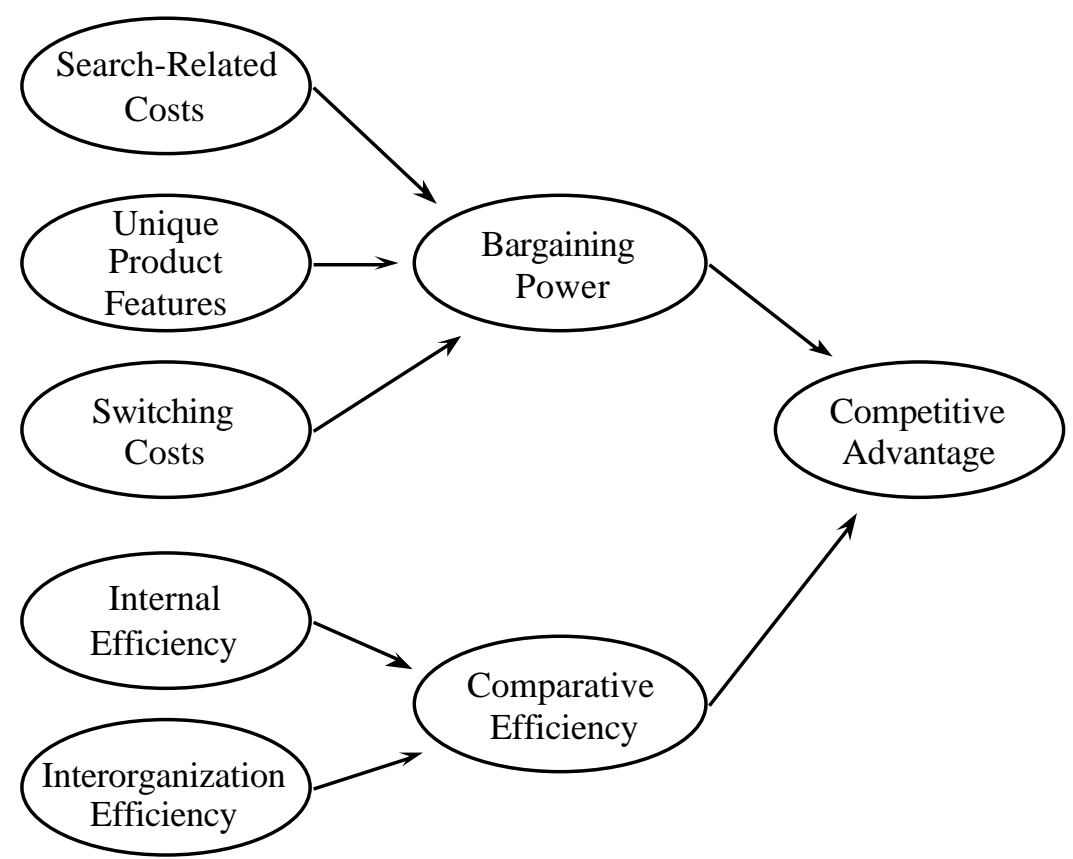

Figure 3. A Causal Model of Competitive Advantage

We have thus suggested three primary determinants of bargaining power: the cost of the search process, unique product features, and switching costs. These factors, illustrated in Figure 3, have symmetric implications for a firm's relationship with its customers and its suppliers. Thus a firm will increase its monopoly power by increasing its customers' relative cost of search for alternative suppliers, by incorporating unique features in its products, and by increasing its customers' cost of switching to alternative suppliers. It can increase its monopsony power by reducing its cost of locating alternative suppliers, its dependence on unique inputs, or its costs of switching to alternative sources of supply.

\section{Comparative efficiency}

We see two major aspects of comparative efficiency: internal (intraorganizational) efficiency, and external (boundary spanning, interorganizational) efficiency. Internal efficiency considerations have been examined in the section on internal strategy, and hence the frameworks developed in that section will be adequate for the categorization and analysis of impacts in this area. Methodologies for the identification of opportunities for comparative efficiency should focus on analyzing the performance of critical organizational functions relative to other firms within the industry. The transaction cost theory pioneered by Williamson [39] provides a natural device to study the impact of information technology at the boundaries between organizations. This work will be further discussed in the next section, in the context of industry-level impacts of information technology. More traditional approaches based on value-addedchain analysis [33] could provide an alternative.

\section{Dynamic considerations}

The above two dimensions create a static picture of the competitive situation, which, like a flat view of the world, fails to capture the dynamic richness of the competitive game as it unfolds. The missing third dimension is timing, and both disciplines of game theory and industrial economics can provide relevant literature. Translating the static 
impacts of information technology into dynamic competitive moves, however, that anticipate competitive responses and create barriers to replication, is an aspect of strategy formulation that lies outside the scope of this paper.

\section{Theoretical links}

We have used industrial economics as the source of theories to study competitive advantage. We now propose two theoretical links between information technology and competitive advantage that can serve as the basis for specific theories that can explain how information technology can improve the competitive strategy of a firm.

Bounded rationality provides the first such link; extending the bounds of organizational rationality has direct implications for both bargaining power and comparative efficiency. In particular, it affects the cost of search (by improving the generation and evaluation of alternatives), as well as transaction costs in organizational interfaces. According to Williamson [39], transaction costs arise from environmental constraints, opportunism, and market exchanges with small numbers of participants, coupled with bounded rationality. Information technology can have a direct impact on these variables through its effect on bounded rationality, for example by reducing contracting and monitoring costs (thus mitigating the effect of opportunism), improving the generation and evaluation of alternatives (thus mitigating the effect of environmental uncertainty and complexity), and either decreasing or increasing information asymmetries.

The second theoretical link between information technology and industrial economics theory comes from the effects of IT on production processes. It is generally accepted that information technology is an inherently flexible technology, improving the adaptability of products, and allowing the realization of scale economies from smaller production runs. It can therefore change the economics of production, and facilitate product differentiation based on unique features. Furthermore, information technology can allow assets to be less specific to the particular economic transactions involved, potentially decreasing the costs of switching to alternative customers and suppliers.

\section{Information Technology and Business Portfolio Strategy}

In the previous sections we have focused our attention on the impact of information technology within an industry and its boundaries. It is likely, however, that information technology will have more macroscopic effects as well, affecting the structure of different marketplaces. Information systems, for example, can help markets be more efficient by increasing the amount of available information, and can lower certain barriers to entry while raising others. Thus, they can cause a shift in the structure of entire industries.

Industry-level impacts of information technology have important strategic implications for the portfolio of industries in which a firm is competing. Specifically, a firm may be able to improve this portfolio by taking advantage of structural changes catalyzed by new technology. Alternatively, a firm can actively seek opportunities to exploit its technology-related skills and resources in new industries. Our understanding of the link between information technology and corporate strategy at this level is currently limited, as demonstrated by the scarcity of existing work on the subject. 


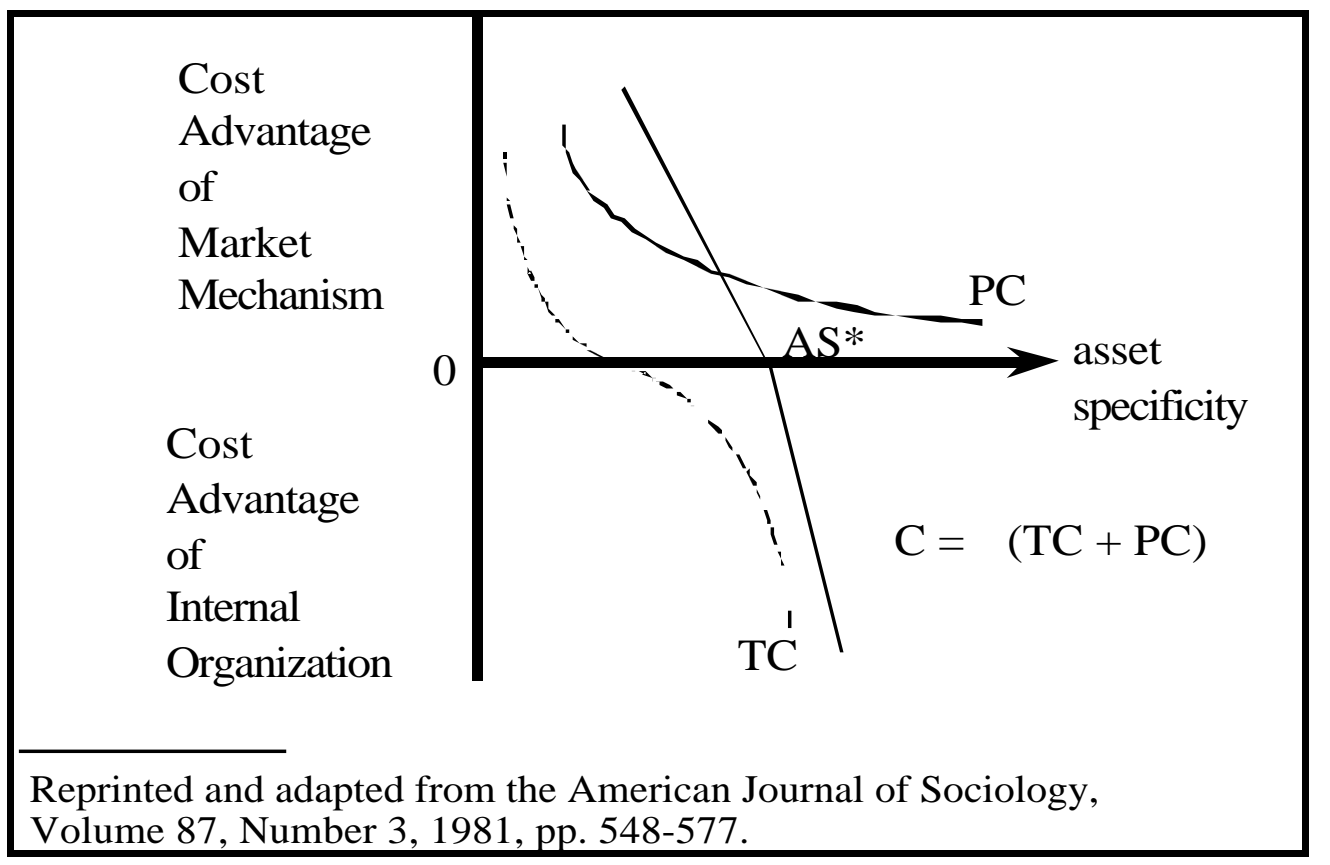

Figure 4. Williamson's Efficient Boundaries Model

\section{Structural impacts of information technology}

Williamson's "efficient boundaries" hypothesis [40] suggests that as asset specificity increases, the transaction cost superiority of the internal organization outweighs the market's advantage in production efficiency, thus driving some exchanges out of the market and leading to internalization of the related transactions. As Figure 4 illustrates, beyond a certain point of asset specificity $\left(\mathrm{AS}^{*}\right)$ the production cost advantage of market mechanisms vs internal organization $(\triangle \mathrm{PC})$ declines and is overshadowed by the lower transaction cost of internal organization, denoted by a negative transaction cost advantage of markets $(\Delta T C)$. Information technology can affect asset specificity by increasing the flexibility of the production processes, it can affect the production cost advantage of markets by changing production economics, such as economies of scale, and finally it can affect the transaction cost advantage of markets through an impact on transaction costs. Information technology will therefore shift the efficient boundaries of organization, affecting the economics of make $v s$. buy decisions, and in the process creating some new markets and causing others to disappear.

Porter's framework of competitive forces [32], derived from industrial economics, suggests a point of view based on the dynamics of an economic game where participants include industry competitors, customers, suppliers, and potential entrants. In that framework, the structural implications of information technology for a particular industry will be determined by its effect on rivalry within the industry, its impacts on the industry's relations with its customers and suppliers, and its implications for prospective entrants and the threat of substitute products.

\section{Exploitation of technology advantage}

Tightly linking strategy formulation with the development of information technology is of growing importance in many industries. One major aspect of this link is the need for a firm's strategy to provide direction for its technological base-building. An alternative 
course is to translate the technological superiority of the firm into opportunities for successful ventures in new industries. In both cases the link between technology and strategy is strengthened, and this can be achieved by strategy-literate information systems planners and technology-literate strategic planners. We see three likely sources of specific theories and models for the creation and exploitation of technology advantage in the context of business portfolio strategy: (1) organizational theories of technology assimilation, such as stage theories; (2) industrial economic theories, such as those related to the economies of scope; and (3) game theory, such as those approaches analyzing the importance of timing.

\section{Concluding Remarks}

As Keen has noted [21], a major problem with past information systems research is the proliferation of frameworks at the expense of explanatory models based on a general theory, and the lack of reference disciplines that can provide appropriate general theories. Much of the current work on the strategic impacts of information technology, despite dramatic references to "strategic tools" and "competitive weapons," makes little or no use of bodies of theory related to either strategy or competition. As the field matures, the primary focus of academic research should move to a deeper level of analysis, characterized by specific, explanatory models connected to broader general theories. Approaches drawing on appropriate reference disciplines can avoid idiosyncratic, private theories of the strategic use of information systems. Assertions and conclusions that are plausibly argued from an accepted point of origin are seen as part of the larger fabric of corporate strategy. The overall result is a contribution to both fields of information systems and corporate strategy. Alternatively, frameworks based on private theories lacking this kind of foundation are of more limited value.

Two bodies of literature closely related to this area of study are organization theory and industrial economics. Work on bounded rationality, human decision making, the value of information, the extraction of monopoly rents, the functioning of markets under imperfect information, barriers to entry, and Williamson's work on transaction costs and organizational boundaries, provide relevant reference theories. This article

demonstrated how these theories can be used to create detailed explanatory models of the impact of information technology on strategic performance. Developing these models and linking them to practice through empirical study defines a major research agenda in this area.

Finally, it is shown how three perspectives of the strategic impact of information systems, (internal, competitive and business portfolio), identify different issues of importance, suggest different theoretical frameworks as the basis for research, and are amenable to different methodologies for opportunity identification. These perspectives are also likely to differ in their appropriate research methods, as they are based on separate theoretical disciplines.

\section{References}

1. Bakos, J. Y. "Toward a More Precise Concept of Information Technology." Proceedings of the Sixth International Conference on Information Systems, L. Gallegos (ed.), Indianapolis, Indiana, December 16-18, 1985, pp. 17-24. 
2. Bariff, M. L. Information Requirements Analysis: A Methodological Review. Working Paper 76-08-02. Decision Sciences Department, Wharton School, University of Pennsylvania, Philadelphia, Pennsylvania, January 1977. Revised December 1977.

3. Benjamin, R. I., Rockart, J. F., Scott Morton, M. S. and Wyman, J. "Information Technology: A Strategic Opportunity." Sloan Management Review,_Volume 25, Number 3, Spring 1984, pp. 3-14.

4. Bullen, C. V. and Rockart, J. F. "A Primer on Critical Success Factors." CISR Working Paper 69, Center for Information Systems Research, Massachusetts Institute of Technology, Cambridge, Massachusetts, June 1981.

5. Business Week. "Foremost-McKesson: The Computer Moves Distribution to Center Stage." December 7, 1981, pp. 115-122.

6. Cash, J. I. and Konsynski, B. R. "IS Redraws Competitive Boundaries." Harvard Business Review,_Volume 63, Number 2, March-April 1985, pp. 134-142.

7. Ciborra, C. U. "Reframing the Role of Computers in Organizations: The Transaction Costs Approach." Proceedings of the Sixth International Conference on Information Systems, L. Gallegos (ed.), Indianapolis, Indiana, December 16-18, 1985, pp. 57-69.

8. Cooper, R. B. and Swanson, E. B. "Management Information Requirements Assessment: The State of the Art." Data Base,_Volume 11, Number 2, Winter 1979, pp. 5-16.

9. Cyert, R. and March, J. A Behavioral Theory of the Firm. Prentice-Hall, Englewood Cliffs, New Jersey, 1963.

10. Davis, G. B. "Strategies for Information Requirements Determination." IBM Systems Journal, Volume 21, Number 1, 1982, pp. 4-30.

11. Fortune. "Merill Lynch Quacks Like a Bank." Volume 102, Number 8, October 20, 1980, pp. 134-144.

12. Fortune. "The Hard-Selling Supplier to the Sick." Volume 106, Number 2, July 26, 1982, pp. 56-61.

13. Galbraith, J. Designing Complex Organizations. Addison-Wesley, Reading, Massachusetts, 1977.

14. Gerstein, M. and Reisman, H. "Creating Competitive Advantage with Computer Technology." Journal of Business Strategy,_Volume 3, Number 1, Summer 1982, pp. 53-60.

15. Hamilton, S. and Chervany, N. L. "Evaluating Information System Effectiveness Part I: Comparing Evaluation Approaches." MIS Quarterly,_Volume 5, Number 3, September 1981, pp. 55-69.

16. Hamilton, S. and Chervany, N. L. "Evaluating Information System Effectiveness Part II: Comparing Evaluation Viewpoints." MIS Quarterly,_Volume 5, Number 4, December 1981, pp. 79-86.

17. Hammer, M. M. and Kunin, J. S. "Design Principles of an Office Specification Language." AFIPS Conference Proceedings, 1980 National Computer Conference, AFIPS Press, Arlington, Virginia., May 1980, pp. 541-547. 
18. International Business Machines Corporation. Business Systems Planning Information Systems Planning Guide, Application Manual GE20-0527-3, IBM Corporation, Armonk, New York, Third Edition, July 1981.

19. Ives, B. and Learmonth, G. P. "The Information System as a Competitive Weapon." Communications of the ACM, Volume 27, Number 12, December 1984, pp. 11931201.

20. Kantrow, A. M. "The Strategy/Technology Connection." Harvard Business Review, Volume 58, Number 4, July-August 1980, pp. 6-21.

21. Keen, P. G. W. "MIS Research: Reference Disciplines and a Cumulative Tradition." Proceedings of the First International Conference on Information Systems, C. Ross (Ed.), Philadelphia, Pennsylvania, December 8-10, 1980, pp. 9-18.

22. Keen, P. G. W. "Information Systems and Organizational Change." Communications of the ACM,_Volume 24, Number 1, January 1981.

23. Keen, P. G. W. "Telecommunications and Business Policy: The Coming Impacts of Communication on Management." CISR Working Paper 81, Center for Information Systems Research, Massachusetts Institute of Technology, Cambridge, Massachusetts, September 1981.

24. Leavitt, H. J., "Applied Organizational Change in Industry." In Handbook of Organizations, J. March (ed.). Rand-McNally, Chicago, Illinois, 1965.

25. Lucas, H. C. Jr. "Performance and the Use of an Information System." Management Science,_Volume 21, Number 8, April 1975, pp. 908-919.

26. March, J. and Simon, H. Organizations. John Wiley and Sons, New York, New York, 1958.

27. McFarlan, F. W. and McKenney, J. Corporate Information Systems Management. Richard D. Irwin Inc., Homewood, Illinois, 1983.

28. McFarlan, F. W. and McKenney, J. L. "Information Systems Planning: a Contingent Focus." Harvard Business School Case \#181-128, HBS Case Services, Boston, Massachusetts, September 1981.

29. Munroe, M. C. and Davis, G. B. "Determining Management Information Needs: A Comparison of Methods." MIS Quarterly, Volume 1, Number 2, June 1977, pp. 5567.

30. Parsons, G. L. "Information Technology: A New Competitive Weapon." Sloan Management Review, Volume 25, Number 1, Fall 1983, pp. 3-14.

31. Parsons, Gregory L. "Fitting Information Systems Technology to the Corporate Needs: The Linking Strategy." Harvard Business School Teaching Note \#9-183176, HBS Case Services, Boston, Massachusetts, June 1983.

32. Porter, M. Competitive Strategy. Free Press, New York, New York 1980.

33. Porter, M. Competitive Advantage. Free Press, New York, New York 1985.

34. Rockart, J. F. "Chief Executives Define Their Own Data Needs." Harvard Business Review,_Volume 57, Number 2, March-April 1979, pp. 81-93.

35. Rockart, J. F. and Scott Morton, M. S. "Implications of Changes in Information Technology for Corporate Strategy." Interfaces,_Volume 14, Number 1, JanuaryFebruary 1984, pp. 84-95. 
36. Simon, H. The Shape of Automation for Men and Management. Harper and Row, New York, New York, 1965.

37. Sirbu, M., Schoichet, S., Kunin, J., Hammer, M. and Sutherland, J. "OAM: An Office Analysis Methodology." Behaviour and Information Technology, Volume 3, Number 1, January 1984, pp. 25-39.

38. Taggert, W. M. and Tharp, M. O. "A Survey of Information Requirements Analysis Techniques." ACM Computing Surveys,_Volume 9, Number 4, December 1977, pp. 273-290.

39. Williamson, O. Markets and Hierarchies. Free Press, New York, New York, 1975.

40. Williamson, O. E. "The Economics of Governance: Framework and Implications." Discussion Paper 153, Yale University, New Haven, Connecticut, July 1983.

41. Zannetos, Z. S. "The Renewal Process and Obstacles to Innovation." Working Paper 1445, Sloan School of Management, Massachusetts Institute of Technology, Cambridge, Massachusetts, June 1983. 